\title{
Induction in gonococci of phenotypic resistance to killing by human serum by human genital secretions
}

\author{
P M V MARTIN,* P V PATEL, $\uparrow$ N J PARSONS, $\uparrow$ AND H SMITH† \\ From the *Unité d'Ecologie Bactérienne, Institut Pasteur, Paris, France, and the TDepartment of \\ Microbiology, University of Birmingham, Birmingham
}

SUMMARY Cervical secretions and seminal plasmas from uninfected clinically healthy persons and vaginal exudates from patients with infections other than gonorrhoea converted gonococci susceptible to killing by fresh human serum to resistance after three hours' incubation at $37^{\circ} \mathrm{C}$. The inducing factors present in the genital secretions explain the serum resistance of gonococci from patients with acute urethritis. This serum resistance is lost on subculture in laboratory media but could play an important role in vivo in the survival of gonococci in the initial stages of urogenital infection when serum factors are liberated into the local infection site during inflammation.

\section{Introduction}

Gonococci obtained from infected patients are resistant to killing by human serum. This resistance is accepted as important in the pathogenesis of gonorrhoea in relation to survival in the bloodstream in disseminated infection. ${ }^{1}$ Less attention has been paid to its possible role in local infections of the mucous membranes and subepithelial tissues, wherf it could be equally important in promoting survival against serum factors which will certainly be liberated into the area by the intense inflammatory response which is evoked by gonococcal infection. A fact sometimes forgotten in the universal acceptance of the serum resistance of strains from disseminated infections ${ }^{2}$ is that gonococcal strains isolated from urethral pus and examined directly without subculture are also resistant to killing by human serum. ${ }^{3}$ The latter resistance is, however, different from the former. Whereas most strains from disseminated infections retain their resistance to human serum on subculture many of the isolates from acute urethritis lose their resistance in laboratory cultures. ${ }^{3}$ We have been interested in this unstable type of resistance-that is, what host factors induce the resistance in vivo that are absent from artificial media. Firstly, using infection of subcutaneously implanted plastic chambers in guinea pigs as a convenient source of serum

Address for reprints: Dr P V Patel, Department of Microbiology, University of Birmingham, South-west Campus, P O Box 363, Birmingham, B15 2TT

Accepted for publication 15 July 1982 (human)-resistant gonococci grown in vivo, it was shown that resistance was phenotypically determined ${ }^{4}$ and induced by factors in guinea pig serum, one of which was of low molecular weight. ${ }^{56}$ Attention then turned to human inducing factors which were found in about $25 \%$ of human sera and in both high and low molecular weight fractions. ${ }^{7}$ In relation to the induction or maintenance of serum resistance in gonococci at the beginning and early stages of mucosal infection, female and male genital secretions have now been examined for resistanceinducing activity.

\section{Materials and methods}

GENITAL SECRETIONS

At Birmingham cervical scrapings were obtained from uninfected, clinically healthy subjects by courtesy of Drs R Condie, K K Chan, R Patel, and H Leung (St Chad's Hospital). Scrapings were collected in saline $(5-10 \mathrm{ml})$ and kept at $-20^{\circ} \mathrm{C}$ until required for tests. After being thawed at $37^{\circ} \mathrm{C}$, the samples were sonicated (Rapidis Ultrasonic SP-957, Ultrasonic Ltd, Shipley, Yorks; 50 watts, $20 \mathrm{kHz}$; four bursts of 30 seconds at room temperature) and centrifuged $(2500 \times g$ for 15 minutes at room temperature). The supernatant fluid was separated, filtered through a Millipore membrane $(0.22 \mu \mathrm{m}$ pore size), and tested for resistance-inducing activity. In the first instance nine samples were bulked for testing and then subsequent samples were tested individually.

At Birmingham seminal plasma was also collected from uninfected, clinically healthy subjects by 
courtesy of Mr C J Lodge (St Chad's Hospital) and Mr P J Adams (Selly Oak Hospital). Each sample (about $2 \mathrm{ml}$ ) was processed without dilution with saline. They were sonicated, centrifuged, and filtered through a Millipore membrane as described for the cervical secretions. Owing to the high viscosity only $0 \cdot 1-0.5 \mathrm{ml}$ of filtered material was available for testing for resistance-inducing activity.

In Paris vaginal exudates were collected by courtesy of Dr F Pean (International Students' Hospital) from 14 clinically infected patients without bacteriologically diagnosed gonorrhoea; the diagnosed infections were viral, one, bacterial other than gonococcal, four, fungal, two, and parasitic, one. All samples $(0 \cdot 2-4 \cdot 5 \mathrm{ml})$ contained about $50 \%$ (v/v) cellular debris. After standing at $4^{\circ} \mathrm{C}$ for $3-4$ hours the samples were diluted with an equal volume of defined medium (see below) at $\mathrm{pH} 7 \pm 0 \cdot 2$. After vortex mixing and centrifuging (3000 $\times g$ for 10 minutes at room temperature) the supernatant fluid was separated, adjusted to $\mathrm{pH} 6 \cdot 6 \pm 0 \cdot 2$, heated for 40 minutes at $56^{\circ} \mathrm{C}$, filtered through Millipore membrane $\left(0 \cdot 22-\mu \mathrm{m}\right.$ pore size) and stored at $-20^{\circ} \mathrm{C}$ until tested for resistance-inducing activity.

SERUM-SENSITIVE NEISSERIA GONORRHOEAE This was strain BS4 (agar) derived, stored, cultured, and viably counted as described. ${ }^{578}$

GENERATION OF RESISTANT ORGANISMS

The method was performed as described. ${ }^{57}$ Briefly the medium $(100 \mu \mathrm{l})$ consisted of a $1: 1$ mixture of a defined medium (DM) ${ }^{5}$ and test sample (see above) at pH $6.6 \pm 0.2$ placed in the wells of Microtiter plates (Flow Laboratories, Irvine, UK). Serum-sensitive gonococci $\left(0 \cdot 5-2 \times 10^{5} \mathrm{ml}^{-1}\right.$ in $10 \mu \mathrm{l}$ of DM) were added and the mixtures incubated for three hours at $37^{\circ} \mathrm{C}$. Estimates of gonococcal multiplication were made by plating out duplicate samples $(10 \mu \mathrm{l})$ of the mixture before and after incubation.

MEASUREMENT OF RESISTANCE TO KILLING BY FRESH HUMAN SERUM

This technique has been described. ${ }^{5}$ The results were expressed as the number of colony forming units (cfu) recovered after incubation of a sample $(4 \mu \mathrm{l})$ of the above suspension of gonococci for $\mathbf{4 0}$ minutes at $37^{\circ} \mathrm{C}$ with fresh human serum (FHS; $10 \mu \mathrm{l}+30 \mu \mathrm{l}$ DM) quoted as a percentage of the cfu obtained when heat-inactivated $\left(56^{\circ} \mathrm{C} ; 60 \mathrm{~min}\right)$ serum was used. The following controls were included.

In each experiment a sample of heat-inactivated human serum known to have negligible resistanceinducing activity was included in the system for generation of resistant organisms; the gonococci so produced were shown to be completely susceptible (less than $1 \%$ survivors) to killing by fresh human serum in the test system described. Also, in the work with cervical secretions and seminal plasmas samples of small molecular weight fractions from guinea pig serum $^{56}$ known to be active or inactive in inducing resistance were included as additional controls. Finally, the absence of appreciable amounts of inhibitors of bactericidal activity (for example, anticomplimentary materials) in the genital secretions was checked by testing the bactericidal activity of FHS against susceptible BS4 (agar) organisms with and without the amount of genital secretion which would have been carried over from the generation of resistant organisms into the bactericidal test.

All samples of genital secretions were tested 2-3 times and typical results are quoted below.

\section{Results}

\section{RESISTANCE INDUCTION}

By cervical secretions from uninfected clinically healthy women

A bulked sample of secretions from nine people consistently converted $50-60 \%$ of the susceptible gonococci to resistance. Eleven individual samples of secretions converted $100 \%, 61 \%, 60 \%, 60 \%, 51 \%$, $48 \%, 46 \%, 30 \%, 26 \%, 20 \%$, and $<10 \%$ of susceptible gonococci to resistance. In all these experiments the number of viable gonococci present at the end of the three-hour conversion period was $80-130 \%$ of those present initially.

By seminal plasmas from uninfected clinically healthy men

In preliminary tests two seminal plasmas both converted $100 \%$ of the susceptible gonococci to resistance. In subsequent tests 10 different seminal plasmas converted $100 \%, 97 \%, 92 \%, 92 \%, 91 \%$, $91 \%, 90 \%, 71 \%, 60 \%$, and $13 \%$ of susceptible gonococci to resistance. Some seminal plasmas had a slight ability to inhibit the bactericidal activity of human serum (see above). With these samples, to make sure that any carry-over of plasma from the conversion mixture did not interfere with the subsequent test for resistance the gonococci were centrifuged (3500 $\times g$ for 10 minutes) at the end of the three-hour conversion period and washed twice with $500 \mu \mathrm{l}$ of $\mathrm{DM}$ containing $0 \cdot 1 \%$ bovine serum albumin before subsequent testing. The results of the resistance tests on these washed gonococci were almost identical with those in which the gonococci were not washed. In all these experiments the number of viable gonococci present at the end of the threehour conversion period was $70-200 \%$ of those 
present initially. Ten additional samples of seminal plasma showed some toxicity to gonococci when used undiluted in the conversion media but twofoldfourfold dilutions of all samples were not toxic and retained substantial resistance-inducing ability.

\section{By vaginal exudates from patients with infections other than gonorrhoea}

Two of the samples of vaginal secretions killed all gonococci in the three-hour incubation period probably owing to the presence of antibiotics from local treatment or to the toxic action of materials liberated from the phagocytes of the local inflammatory response. Of the remaining 12 samples, four showed distinct resistance-inducing activity converting $34 \%, 50 \%, 67 \%$, and $100 \%$ of the susceptible gonococci to resistance in three hours at $37^{\circ} \mathrm{C}$, two had low activity (conversion less than $20 \%$ ), and the remainder appeared inactive. At the end of the three-hour conversion period for the active samples the number of viable gonococci was $110-230 \%$ of those present initially.

\section{Discussion}

Genital secretions from both women and men contain factor(s) which render gonococci resistant to killing by human serum, and the presence of these factors explains the serum resistance of gonococci examined directly from patients with acute urethritis. ${ }^{3}$ The resistance-inducing activity of seminal plasma recalls the demonstration that addition of extract of prostate gland to laboratory media preserved the serum resistance of recent gonococcal isolates. ${ }^{9}$ In this respect it is interesting that three of the 10 inducer-positive samples of seminal plasma (see results) came from subjects who had had vasectomies. Preliminary ultrafiltration experiments similar to those reported for guinea pig and human serum ${ }^{6}{ }^{7}$ indicated that the resistance inducing factor(s) in cervical secretions are present in similar low molecular-weight fractions. ${ }^{6}$

It is difficult to believe that the serum resistance of gonococci on and within genital epithelium does not play a role in survival in the initial stages of infection. While it is true that there is no direct evidence that the gonocidal factors in human serum are liberated into the local genital sites during inflammation this almost certainly happens, because there is good reason to believe that the lethal factors are natural antibody and complement which would, without doubt, be mobilised to the site of infection.
In the present study no attempt was made to assess the relative amounts of resistance-inducing factors in the different secretions examined and in the individual samples of each secretion. Clearly, the seminal plasmas were examined in a more concentrated form than the saline extracts of the cervical secretions and the DM-diluted vaginal secretions. In view of the probable importance of the inducing factors in the pathogenesis of gonorrhoea a more comprehensive and quantitative survey of genital secretions from various sources may be warranted. This would be easier to accomplish if the chemical nature of the inducer was known. Work to this end is in progress.

Finally, this study has underlined the fact that most gonococci whether they are causing local or disseminated infection are resistant in vivo to killing by human serum. Hence, the ability of some strains to cause disseminated infection must rely on pathogenic mechanisms in addition to being resistant to killing by human serum.

Our thanks are due to Dr E Boxall, of the East Birmingham Hospital, for checking that all samples of cervical secretions and seminal plasmas were free from hepatitis B virus.

\section{References}

1. Brooks GF, Gotschlich EC, Holmes KK, Sawyer WD, Young FE. Immunobiology of Neisseria gonorrhoeae. Washington DC: American Society for Microbiology, 1978.

2. Schoolnik GK, Buchanan TM, Holmes KK. Gonococci causing disseminated gonococcal infection are more resistant to the bactericidal action of normal human sera. J Clin Invest 1976;58:1163-73.

3. Ward ME, Watt PJ, Glynn AA. Gonococci in urethral exudate possess a virulence factor lost on subculture. Nature 1970;227:382-4.

4. Rittenberg SC, Penn CW, Parsons NJ, Veale DR, Smith H. Phenotypic changes in the resistance of Neisseria gonorrhoeae to killing by normal human serum. J Gen Microbiol 1977;103:69-75.

5. Veale DR, Penn CW, Smith $\mathbf{H}$. Factors affecting the induction of phenotypically determined serum resistance of Neisseria gonorrhoeae grown in media containing serum or its diffusible components. J Gen Microbiol 1981;122:235-45.

6. Veale DR, Penn CW, Parsons NJ, Smith H. Preliminary studies of a factor in guinea pig serum which induces serum resistance in Neisseria gonorrhoeae. Soc Gen Microbiol Quart 1980;7:188

7. Martin PMV, Patel PV, Parsons NJ, Smith H. Induction of phenotypically determined resistance of Neisseria gonorrhoeae to human serum by factors in human serum. J Gen Microbiol 1981;127:213-7.

8. Penn CW, Veale DR, Smith $H$. Selection from gonococci grown in vitro of a colony type with some virulence properties of organisms adapted in vivo. J Gen Microbiol 1977; 100:147-58.

9. Watt P, Glynn AA, Ward ME. Maintenance of virulent gonococci in laboratory culture. Nature 1972;236:186-7. 